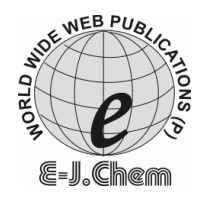

\title{
Combined Anaerobic-Aerobic Bacterial Degradation of Dyes
}

\author{
R.WILFRED SUGUMAR* ${ }^{*}$ and SANDHYA SADANANDAN \\ Department of Chemistry \\ Madras Christian College, Chennai -600 059, India. \\ wilfmcc@rediffmail.com
}

Received 12 September 2009; Revised 24 December 2009; Accepted 15 February 2010

\begin{abstract}
Wastewaters from the dye baths of a non-formal textile-dyeing unit containing C.I. Acid Orange 7 and C.I. Reactive Red 2 were subjected to degradation in a sequential anaerobic-aerobic treatment process based on mixed culture of bacteria. The technical samples of the dyestuffs and the dye bath wastes were treated in an anaerobic reactor, using an adapted mixed culture of anaerobic microorganisms. The dyestuffs were biotransformed into colourless substituted amine metabolites in the reactor. The biotransformation was assisted by cometabolic process. The amine metabolites did not undergo further degradation in the anaerobic reactor. The effluent from the anaerobic reactor was treated in an aerobic rotating biological contactor and the amine metabolites were found to undergo complete mineralization. This two stage treatment resulted in $94 \%$ elimination of dissolved organic carbon. In addition, $85 \%$ of organic nitrogen was converted into nitrate in the aerobic reactor during nitrification process.
\end{abstract}

Keywords: Acid Orange 7, Reactive Red 2, Anaerobic reactor, Aerobic reactor, Biotransformation, Biodegradation.

\section{Introduction}

Dyes containing azo groups are one of the largest classes of commercial dyes used in textile industry. Over the last decades, the increasing demand for dyes by the textile industry has shown a high pollutant potential. It is estimated that around $10-15 \%$ of the dyes are lost in the wastewater during the dyeing processes. Thus they make up the vast majority of the dyes discharged by textile-processing industries.

Many dyes are visible in water at concentrations as low as $1 \mathrm{mg} \mathrm{L}^{-1}$. Textile-processing wastewaters, typically with dye content in the range 10 to $200 \mathrm{mg} \mathrm{L}^{-1}$, are therefore usually highly coloured and their discharge in water bodies presents an aesthetic problem. As dyes are designed to be chemically and photolytically stable, they are highly persistent in natural environments. The release of dyes may therefore present an ecotoxic hazard and introduces the potential danger of bioaccumulation that may eventually affect humans by transport through the food chain. Azo dyes in purified form are seldom directly mutagenic or carcinogenic, except for some azo dyes with free amino groups. 
However, reduction of azo dyes, i.e. cleavage of the dye's azo linkage(s), leads to formation of aromatic amines and several aromatic amines are known mutagens and carcinogens. In mammals, metabolic activation of azo dyes is mainly due to bacterial activity in the anaerobic parts of the lower gastrointestinal tract. Various other organs, especially the liver and the kidneys, can, however, also reduce azo dyes ${ }^{1}$.

Due to their stability and xenobiotic nature, azo dyes are not totally degraded or exhibit slow degradation by conventional wastewater biological treatment processes ${ }^{2-4}$. Although the efficiency of advanced oxidation processes for degradation of recalcitrant compounds has been extensively documented, their use for removal of dyes from textile wastewater has some drawbacks, such as high operating and equipment costs ${ }^{5}$.

Hence, in the present study, an adapted mixed culture of anaerobic microorganisms was used to biotransform these dyes and the biotransformed metabolites were subsequently mineralized in an aerobic reactor ${ }^{6}$.

\section{Experimental}

The culture medium for the growth of microorganisms was prepared by mixing the following chemicals in tap water. As the tap water showed excellent buffering capacity, the use of external buffers was avoided ${ }^{7}$. This stock solutions urea $(1.0 \mathrm{mg} / \mathrm{L})$, flesh extract $(9.0$ $\mathrm{mg} / \mathrm{L})$, molasses $(0.10 \mathrm{mg} / \mathrm{L}), \mathrm{NaCl}(0.20 \mathrm{mg} / \mathrm{L}), \mathrm{CaCl}_{2} \cdot 2 \mathrm{H}_{2} \mathrm{O}(0.10 \mathrm{mg} / \mathrm{L}), \mathrm{MgSO}_{4} \cdot 7 \mathrm{H}_{2} \mathrm{O}$ $(0.05 \mathrm{mg} / \mathrm{L})$ and $\mathrm{KH}_{2} \mathrm{PO}_{4}(0.33 \mathrm{mg} / \mathrm{L})$ were appropriately diluted to the desired mixed liquor solid suspension (MLSS) for each study

The technical samples of the dyes C.I. Acid Orange 7 and C.I. Reactive Red 2 were obtained from Aldrich-Chemie Ltd, Germany and dye bath wastewater containing these dyes were collected from a local dyeing unit. The structures of these dyes are shown in Figure 1. The other chemicals used in this study were of AnalaR grade.<smiles>[NH3+]c1ccc(S(=O)(=O)[O-])cc1/N=N/c1cc2ccccc2cc1O</smiles>

Acid Orange 7<smiles>[NH3+]OS(=O)(=O)c1cc(Nc2nc(Cl)nc(Cl)n2)c2c(O)c(N=Nc3ccccc3)c(S(=O)(=O)O[Na])cc2c1</smiles>

Reactive Red 2

Figure 1. Structural formulae of the dyes.

\section{Anaerobic reactor}

The anaerobic reactor consisted of cylindrical tank of six-liter capacity. The wastewater containing the reactive dyes was fed into the anaerobic reactor at the flow rate of $125 \mathrm{~mL} / \mathrm{h}$. This corresponded to a retention time of 48 hours. The mixed liquor from the reactor was sent to the inverted pyramid-like Plexiglas sling tank. After separating the biomass the effluent was fed into the rotating biological contactor. When required, the effluent was mixed with an appropriate amount of organic substances to bring the dissolved organic carbon level to $350 \mathrm{mg} / \mathrm{L}$. 


\section{Aerobic reactor}

The rotating biological contactor unit (RBC) consisted of a tank of $12 \mathrm{~L}$ capacity. A series of plastic discs were mounted on a horizontal shaft that transverse the length of the tank. There were 95 discs, each with a diameter of $10.5 \mathrm{~cm}$. This corresponded to a total growth area of $1.7 \mathrm{~m}^{2}$. The discs were separated by a distance of $1.3 \mathrm{~cm}$ and they were submerged in the tank to about 40 per cent of the disc diameter. The wastewater from anaerobic reactor was pumped into the unit at the rate of $8 \mathrm{~L}$ per day. This corresponded to a retention time of 1.5 days. To determine the effectiveness of the reactors, the following analytical determinations were carried out.

DOC

Carbon dioxide formed by the complete oxidation (combustion at $900{ }^{\circ} \mathrm{C}$ ) of an aliquot was determined by measuring infrared absorption. (Maihak, TocoR-2 DOC analyzer).

Dyes

The concentrations of the technical samples of the dyes C.I. Reactive Black 5 and C.I. Reactive Red 120 were determined by measuring the absorbance at 580 and $540 \mathrm{~nm}$ respectively. The percent decolourisation $\left\{\mathrm{R}_{\mathrm{dc}}(\%)\right\}$ of the wastewater was determined using the formula

$$
\mathrm{R} d c(\%)=\frac{\sum \mathrm{A}_{\mathrm{b}}-\sum \mathrm{A}_{\mathrm{a}}}{\sum \mathrm{A}_{\mathrm{b}}}
$$

Where $\mathrm{A}_{\mathrm{a}}=$ absorbance of treated wastewater at wavelength interval of $10 \mathrm{~nm}$ and $\mathrm{A}_{\mathrm{b}}=$ corresponding term for untreated wastewater

In addition, total Kjeldhal nitrogen, ammonia nitrogen, nitrite and nitrate nitrogen were determined. The metabolites of the dyes were identified by HPLC (Hewlett Packard). The chromatograph was equipped with two reverse phase C18 columns $(200 \times 3 \mathrm{~mm}$, Chromosphere $\mathrm{C} 18$, Chrompack) at $20{ }^{\circ} \mathrm{C}$. The carrier liquid, a $0.5 \%$ acetic acid solution at pH 5.9 was pumped at a flow rate of $300 \mu \mathrm{L} \mathrm{min}{ }^{-1}$. Sulphalinic acid was detected spectrophotometrically, using a Spectroflow 783 UV detector at $248 \mathrm{~nm}$.

\section{Results and Discussion}

\section{Anaerobic biotransformation}

Under anaerobic conditions, the azo linkage in the reactive dyes was reduced and the large dye molecule was broken into fragments. The anaerobic inoculum was found capable of reducing the dyes even in the absence of external electron donor substances. The stoichiometric reduction requires four reduction equivalents. ${ }^{8}$. In the absence of external donors, these reduction equivalents were obtained by dissimilating intracellular storage compounds (Scheme 1).

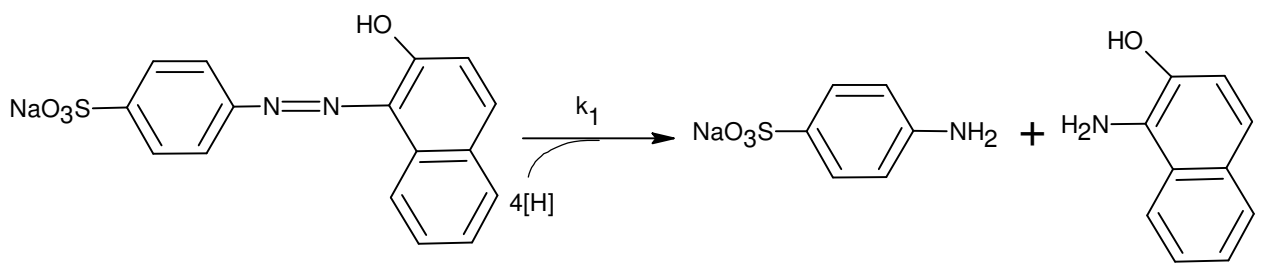

Scheme 1. Anaerobic cleavage of Acid Orange 7. 


\section{Elimination of DOC}

The DOC elimination was not very significant during anaerobic biotransformation of the reactive dyes. The average DOC removal was only $20 \%$. As the dye was only reduced to its amine metabolites, there was no DOC removal with respect to the dye. The low DOC removal is attributed to the elimination of other organic growth substrates. Even the higher DOC removal, observed when the retention time was increased, corresponded only to the removal other substrates and not the dyes. The identification of metabolites confirms absence further biodegradation with respect to the dyes (Figure 2). These results confirmed that the amine metabolites formed were not biodegraded under anaerobic conditions ${ }^{9}$.

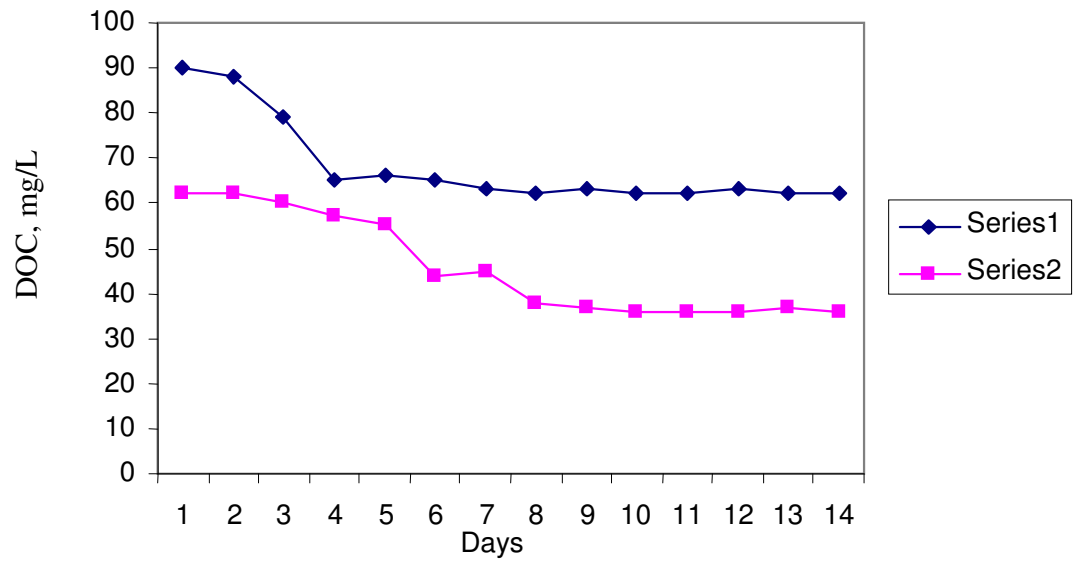

Figure 2. DOC elimination - anaerobic conditions.

\section{Aerobic degradation of amine metabolites}

The effluent from the settling tank, when needed, was mixed with requisite quantity of added substrates to achieve a DOC level of $350 \mathrm{mg} / \mathrm{L}$. The total nitrogen content was $119 \mathrm{mg} / \mathrm{mL}$ and ammonia nitrogen was $20 \mathrm{mg} / \mathrm{L}$. The COD corresponded to a value of $940 \mathrm{mg} / \mathrm{L}$. Most of the dissolved organic carbon was removed readily in RBC. 80\% of DOC removal was observed in the third disc itself and further DOC elimination continued till the $30^{\text {th }}$ disc $^{10}$. After this disc, the DOC of the wastewater remained almost constant giving an outlet DOC of $30 \mathrm{mg} / \mathrm{L}$ (Figure 3). The results confirm that the amine metabolites, which were not degraded in anaerobic reactor, were readily degraded aerobically (Figure 4).

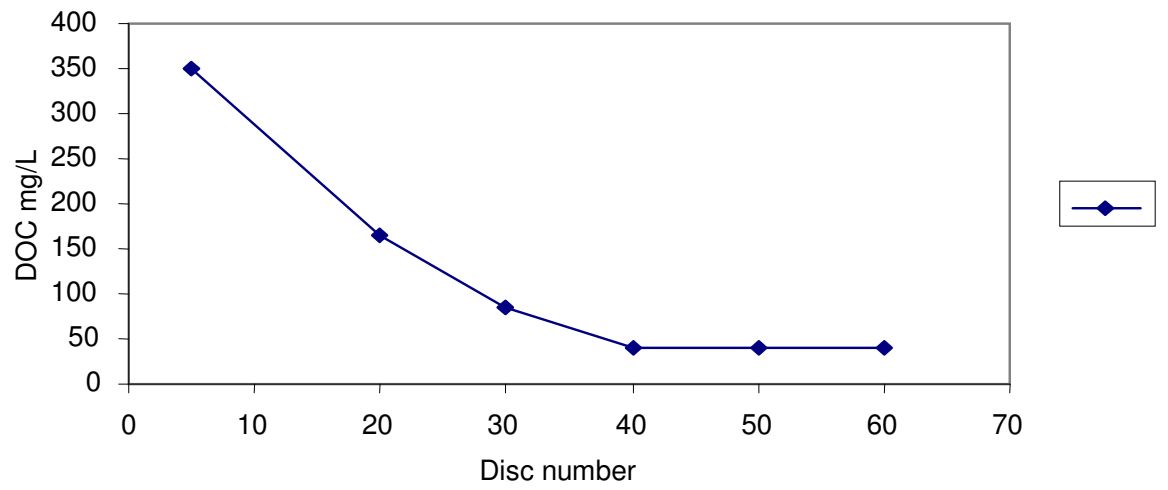

Figure 3. DOC elimination -aerobic conditions. 


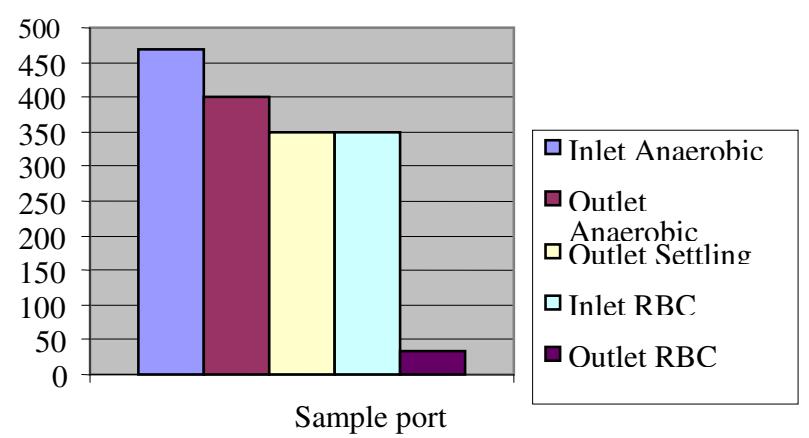

\section{Nitrification}

Figure 4. DOC removal in the two-stage reactor.

The changes that occurred in different forms of nitrogen in the rotating biological contactor are shown in Figure 5. The nitrification was found to be almost complete at the $30^{\text {th }}$ disc. The DOC value reached its minimum at this disc ${ }^{11}$. The nitrifying bacteria are chemoautotrophs and their growth rate is very low compared to the heterotrophic bacteria. The energy obtained by the nitrification process is also not very high. In addition, the nitrifying bacteria have a larger generation time. All these factors mean that the nitrifying bacteria can appear in the reactor only when most of organic matter is degraded. The heterotrophic bacteria while degrading the organic matter produce ammonia. This ammonia, which gets dissolved in water, is then used up by the nitrifying bacteria. Therefore the maximum concentration of the nitrate ion is found only after the $30^{\text {th }}$ disc. Part of organic nitrogen still remained in the outlet indicating the presence of nonbiodegradable organic matter ${ }^{12}$.

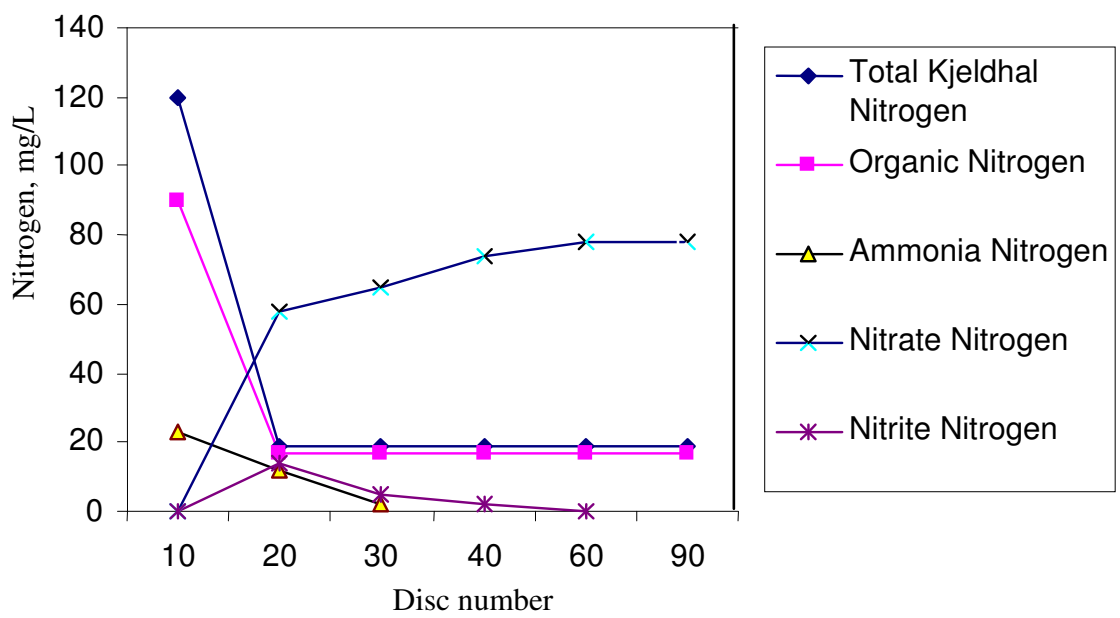

\section{Conclusion}

Figure 5. Nitrification curves.

The studies confirm that the dye wastes containing reactive dyes can be completely biodegraded in a two stage anaerobic -aerobic reactor and the reactor is also capable of achieving complete nitrification. 


\section{References}

1. $\quad$ Cartwright R A, Environ Health Persp., 1983, 4913-4919.

2. Altinbas U, Dokmeci S and Baristiran A, Environ Technol., 1995, 16, 389-394.

3. Togo C A., Cecil Clifford Z M and George Whiteley C, Afr J Biotechnol., 2008, 7(2), 114-121.

4. Barragán B E, Carlos Costa and Carmen Ma'rquez M, Dyes and Pigments, 2007, 75, 73-81.

5. Gomes de Moreas S, Sanches Freire R and Durán N, Chemosphere, 2000, 40, 369-373.

6. An H, Qian Y, Gu X S and Tang W Z, Chemosphere, 1996, 33, 2533-2542.

7. Carliell C M, Barclay S J, Naidoo N, Buckley C A, Mulholland D A and Senior E, Water SA, 1994, 20, 341-344.

8. Panswad T, Iamsamer K and Anotai J, Biores Technol., 2001,76, 151-159.

9. Chinwekitvanich S, Tuntoolvest M and Panswad T, Water Res., 2000, 34, 2223-2232.

10. Lourenço N D, Novais J M and Pinheiro H M, Water Sci Technol., 2000, 42, 321-328.

11. Cruz A and Buitrón G, Water Sci Technol., 2001, 44, 159-166.

12. Kalyuzhnyi S. and Sklyar V, Water Sci Technol., 2000, 41, 23-30. 


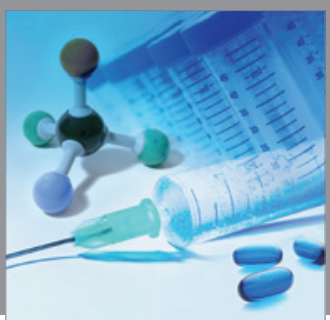

International Journal of

Medicinal Chemistry

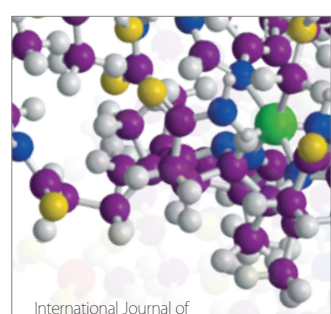

Carbohydrate Chemistry

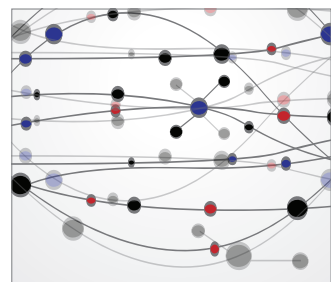

The Scientific World Journal
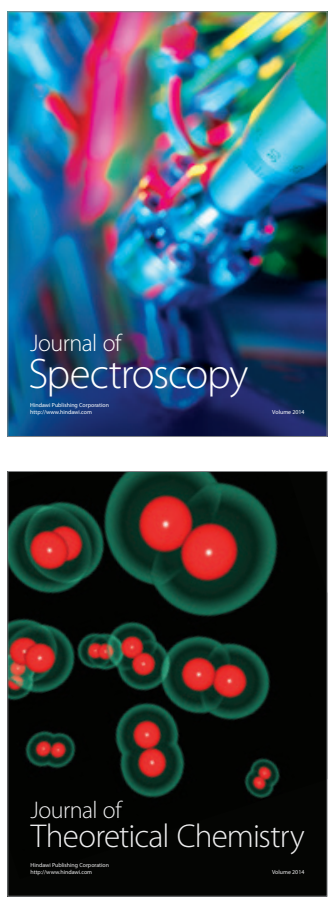
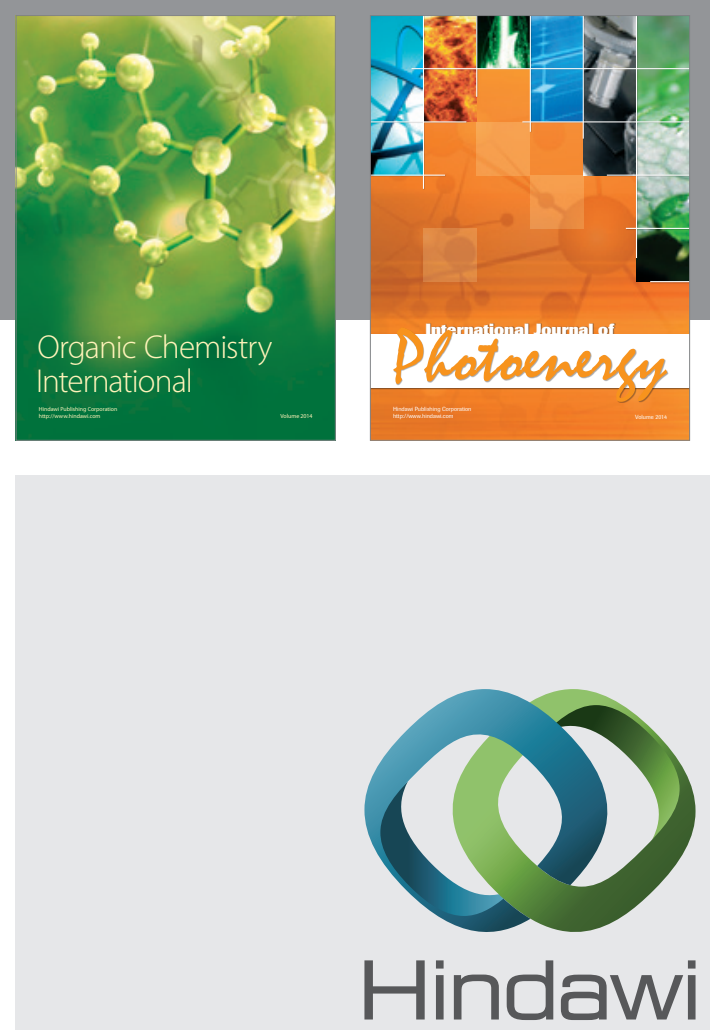

Submit your manuscripts at

http://www.hindawi.com
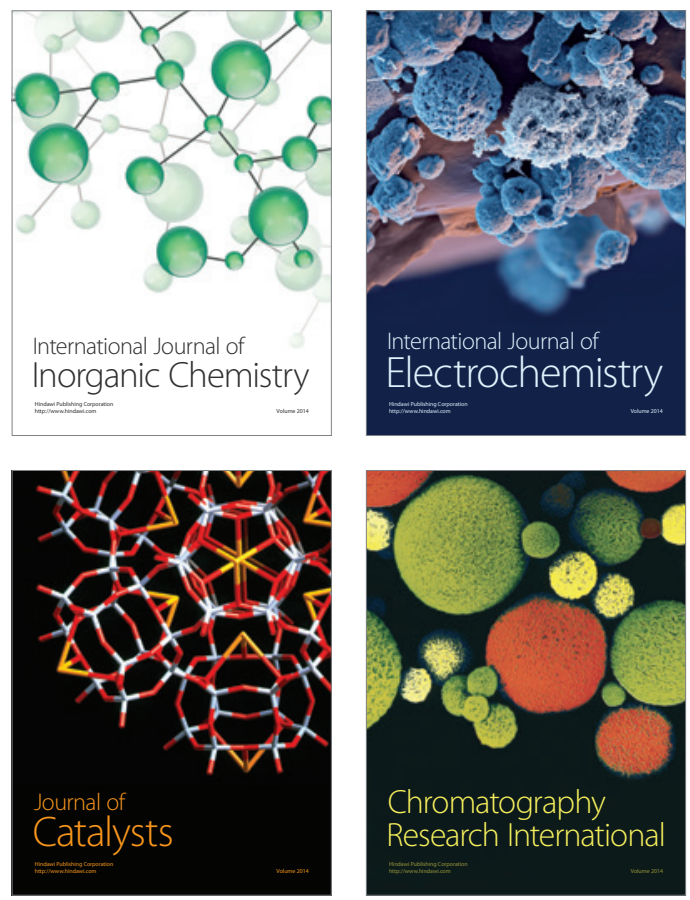
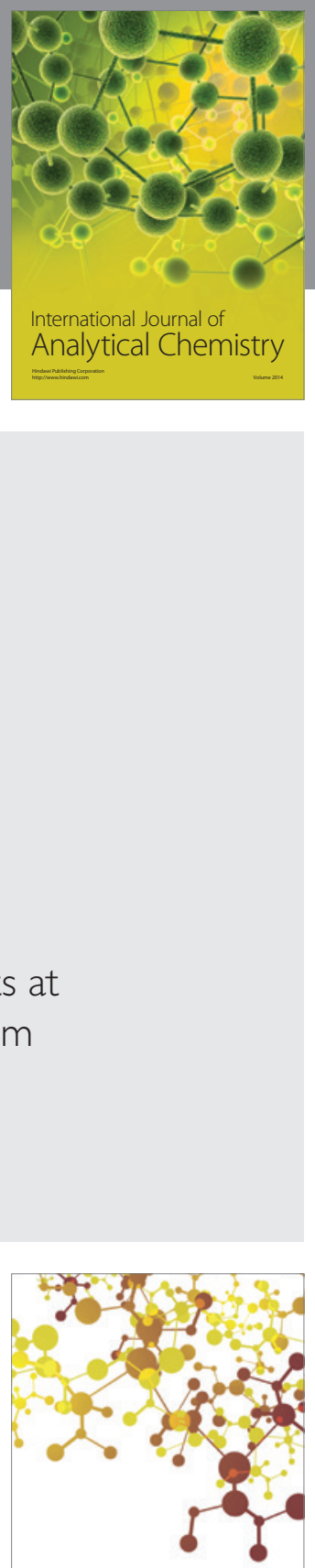

Journal of

Applied Chemistry
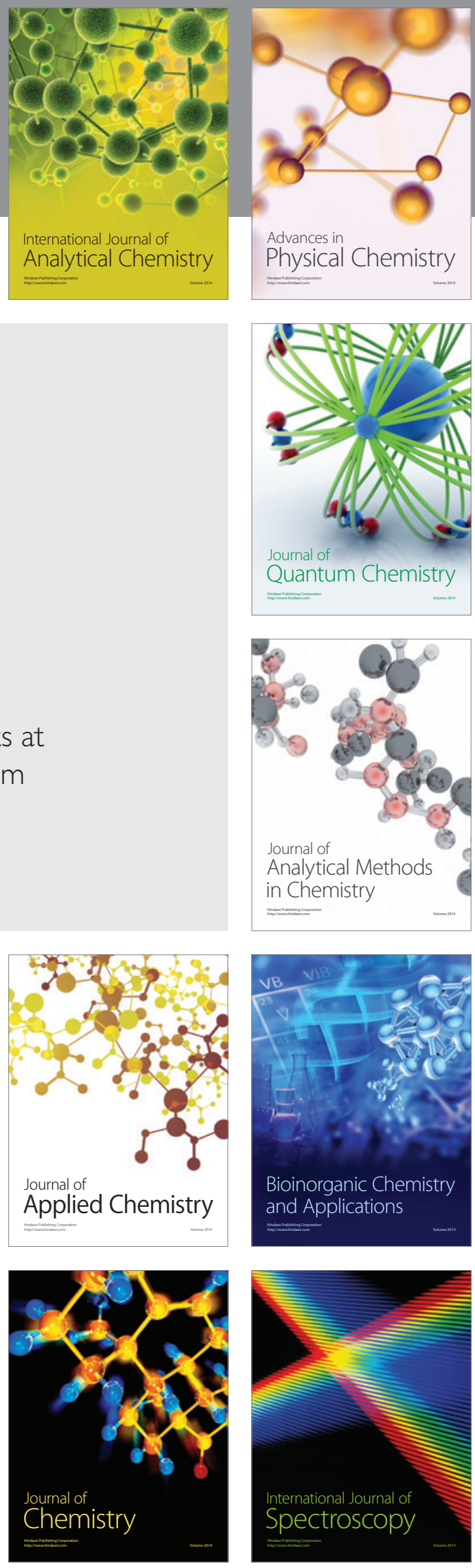